American Journal of Pharmaceutical Education 2020; 84 (9) Article 847515.

\title{
RESEARCH
}

\section{Examining the Disconnect Between Communities of Practice Learning Theory and Educational Practices in the PharmD Program in Qatar}

\author{
Banan Abdulrzaq Mukhalalati, $\mathrm{PhD}^{\mathrm{a}}$, Andrea Taylor, $\mathrm{PhD}^{\mathrm{b}}$ \\ ${ }^{a}$ Qatar University, Qatar Health Cluster, College of Pharmacy, Doha, Qatar \\ ${ }^{\mathrm{b}}$ University of Bath, Department of Pharmacy and Pharmacology, Bath, United Kingdom \\ Submitted January 9, 2019; accepted February 14, 2020; published September 2020.
}

\begin{abstract}
Objective. To examine the Qatar University Doctor of Pharmacy (PharmD) program for evidence of incorporation of communities of practice $(\mathrm{CoP})$ learning theory.

Methods. A developed CoP framework was used as a theoretical instrument to analyze the evidence of CoP theory in QU PharmD program, utilizing a case study research approach.

Results. The research suggests that the evidence of the CoP framework in the PharmD program falls into three categories. The first category represents elements of $\mathrm{CoP}$ that were fully evident, such as knowledge recontextualization, social and professional acceptance, and effective assessment measures. The second category represents elements that were partially evident, such as the formation of a co-development team, informal learning, mentoring strategies, and preceptors' orientation to assessment. The third category represents elements that were not evident, such as collaboration between faculty and preceptors and ensuring the reliability and validity of assessment tools. In cases where elements of CoP were implemented, this was an implicit rather than explicit application of $\mathrm{CoP}$ theory. Therefore, it was theorized that the disconnect between $\mathrm{CoP}$ learning theory and educational practices is at the "implicit disconnect" level.

Conclusion. This research indicates that the $\mathrm{CoP}$ framework facilitated the identification of areas for future quality improvement and suggests that the theoretical $\mathrm{CoP}$ framework could be used by other programs to identify areas for improvements. We theorize that a full and explicit implementation of learning theory into educational practices is crucial, which calls for the collaboration of academic, practice, accreditation, and governmental sectors in pharmacy educational reform initiatives.
\end{abstract}

Keywords: learning theories, communities of practice, case study methodology, social constructivism, Doctor of Pharmacy program

\section{INTRODUCTION}

Qatar, as a Gulf Coast Corporation country, has undergone a remarkable escalation in economic status, with increased tailored funds for health care services. Thousands of health care professionals are needed to meet health care demand across the region, which necessitates hiring qualified clinical pharmacists. ${ }^{1,2}$ The establishment of the Qatar University College of Pharmacy in 2006 aimed to meet Qatar's growing demand for pharmacy services and to achieve Qatar National Vision 2030 by graduating skilled pharmacists. ${ }^{3}$

The college offers an entry to practice Bachelor of Sciences (BSc) degree program and four graduate programs: the Doctor of Pharmacy (PharmD), the Master of Sciences (MSc) in Pharmaceutical Sciences, MSc in

Corresponding Author: Banan Abdulrzaq Mukhalalati, Qatar University, Qatar Health Cluster, College of Pharmacy, PO Box 19920, Doha, Qatar. Tel: +974-558446783. Email: banan.m@qu.edu.qa
Clinical Pharmacy Practice, and a Doctor of Philosophy $(\mathrm{PhD})$ in Pharmaceutical Sciences. ${ }^{4}$ The PharmD program was launched in 2011 to develop advanced clinically trained pharmacists by placing students in practice placements where they are supervised by clinical pharmacy preceptors. ${ }^{2,5}$ In 2014, the PharmD program was accredited as an entry-to-practice PharmD degree by the Canadian Council for Accreditation of Pharmacy Programs (CCAPP). ${ }^{6,7}$

The college explains the PharmD pedagogical approach as an "innovative ability-based curriculum and a student-centered approach to teaching and learning, ${ }^{1}$ however, the college is not explicit about the basis on which this approach was followed in designing the program. Several articles in pharmacy education literature have discussed educational ideology and pedagogy. However, few have focused on evaluating the extent to which a particular pedagogy is implemented within an educational program. Careful consideration of the theoretical nature and 


\section{American Journal of Pharmaceutical Education 2020; 84 (9) Article 847515.}

epistemology of a pharmacy education program is fundamental because it provides insights into how to reduce the challenging gap between pharmacy education and practice. ${ }^{8}$ This lack of published studies evaluating the implementation of a particular pedagogy within an educational program suggests a potential disconnect between learning theories and educational practices in pharmacy programs, ${ }^{9}$ which calls for a more theoretical development of pharmacy education programs. ${ }^{8,10,11}$

All research studies begin with the selection of a topic, an interpretative framework, and a compatible research approach. ${ }^{12}$ Interpretative frameworks are the social science theories that structure the theoretical lenses of qualitative research. ${ }^{13}$ Social constructivism is an interpretative framework that emphasizes process and contexts, and considers the subjective and social negotiation of meanings while recognizing the influence of researchers' values. ${ }^{13}$ Social constructivism influenced educational researchers in developing social learning theories, which integrate behavior modeling and cognitive learning. ${ }^{14-17}$ Vygotsky was the first scholar in sociocultural constructivism, a social theory of learning, to emphasize the situated dimension of learning through learning communities. ${ }^{18}$ Vygotsky's ideas were further developed into situated cognition ${ }^{19}$ and communities of practice theories. ${ }^{20-22}$

A community of practice, which represents a social approach to learning, can be defined as a group of people who share a strong interest in, concern for, and knowledge about something they do and, by interacting, learn how to do it better. ${ }^{9,20,21}$ Austin and Duncan-Hewitt proposed a fundamental restructuring of pharmacy education informed by the communities of practice theory, ${ }^{23}$ where students, practitioners, and faculty members work together and learn from one another. ${ }^{10}$ Several studies have indicated that communities of practice is a suitable theory for curricular restructuring in pharmacy education because it emphasizes context and social participation. ${ }^{8,9,24,25}$ Furthermore, the theories behind communities of practice align with recent developments in pharmacy education that suggest providing students with opportunities to practice by placing them in actual pharmacy practice settings. ${ }^{9,26-28}$

The suggested restructuring of pharmacy education in the direction of communities of practice ${ }^{8,10,11,23}$ led to the development of the first theoretical communities of practice-based framework by Mukhalalati and Taylor. ${ }^{9}$ The communities of practice framework was developed through a rigorous process of an extensive literature review using the Matrix Method, and was peer reviewed by selected health-care education scholars. ${ }^{9,29,30}$ The development of communities of practice framework involved conceptualizing six components (enablers, challenges, curriculum, teaching strategies, assessment, and outcomes; Table 1), which are subdivided into elements (Figure 1). ${ }^{9}$ The developed communities of practice-based framework is intended to be used in the development of pharmacy educational programs to understand the interaction between learning theories and education practices. ${ }^{9}$

This study examined the role of communities of practice learning theory in the design and implementation of the PharmD program at QU by answering the following research questions: What elements of the communities of practice theory are evident in the design and implementation of the QU PharmD program? Is there a disconnect between learning theories and educational practices in the QU PharmD program, and if so, what is the nature of this disconnect?

Table 1. Definitions of the Components of the Communities of Practice Framework Used in a Study of Practice Learning Theory and Educational Practices in the Doctor of Pharmacy Program at Qatar University

(n)

Components

Definition

\begin{tabular}{ll}
\hline Influencing Factors & \\
Enablers (E) & Ideal conditions for implementation \\
Challenges $(\mathrm{CH})$ & Factors that hinder implementation
\end{tabular}

Education Process Pillars

Curriculum (C)

Content, syllabus, learning outcomes, planned formal and informal learning, and extracurricular and learning activities provided in order to achieve professional competence

Teaching strategies (TS) Strategies that are based on the active engagement of students in their learning (student-centered model) in practice placement, where learning from and in practice is the fundamental aspect in education

Assessment (A)

A learning experience that measures learning outcomes, student performance, and progression, and gives the opportunity for constructive feedback

Outcomes

Outcomes (O) The positive outcomes that result from CoP implementation

The definitions for this study were adapted from "The Development of a Theory-Informed Communities of Practice Framework for Pharmacy and Other Professional Healthcare Education Programmes" 


\section{American Journal of Pharmaceutical Education 2020; 84 (9) Article 847515.}

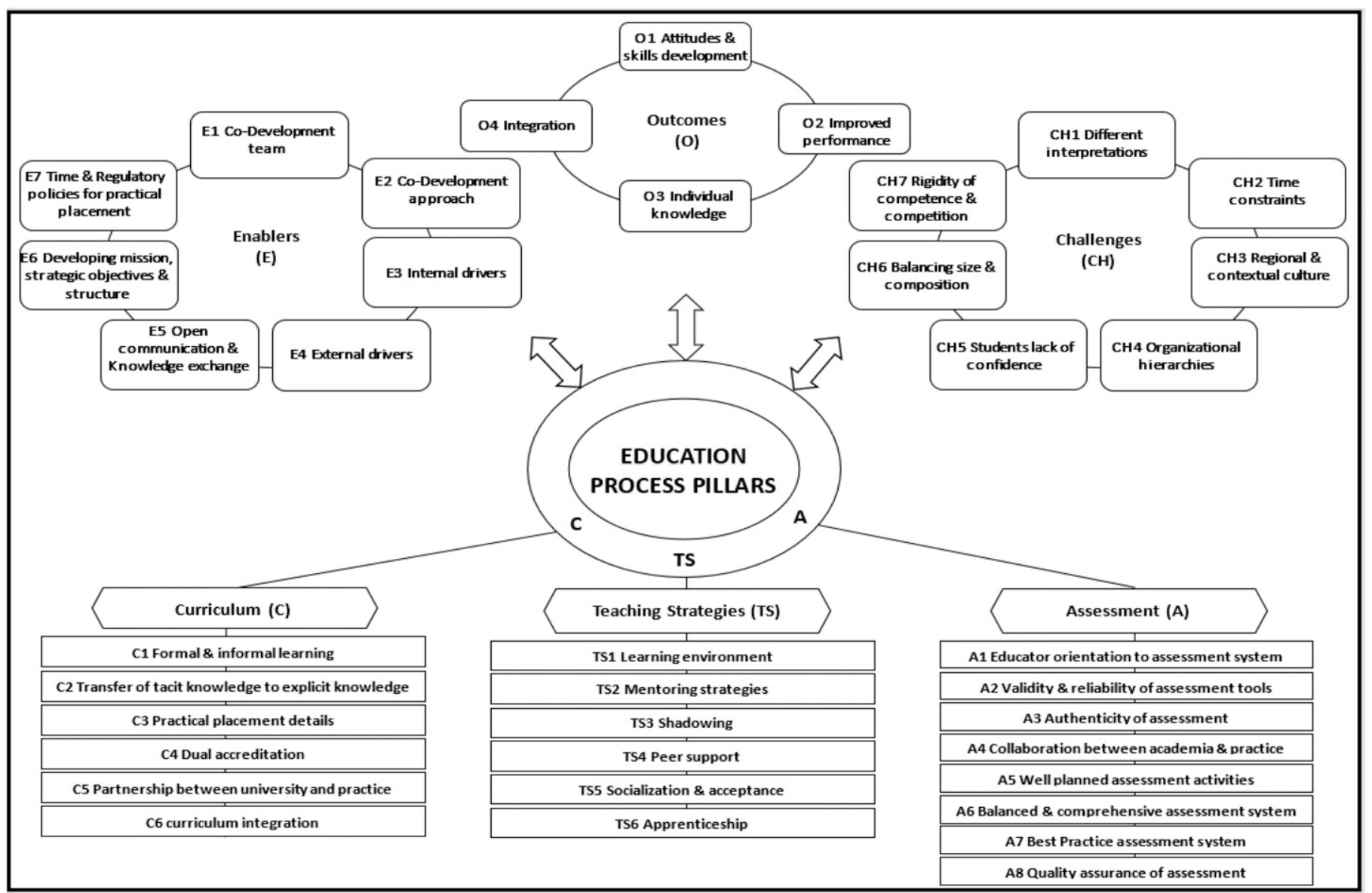

Figure 1. The Components and Elements of the CoP Framework

Adapted from the development of a theory-informed Communities of Practice Framework for pharmacy and other professional healthcare education programmes. ${ }^{9}$

The developed communities of practice-based framework ${ }^{9}$ is used to answer the research questions by providing a theoretical instrument for analyzing the QU PharmD program, while discerning four levels of

Learning Theories

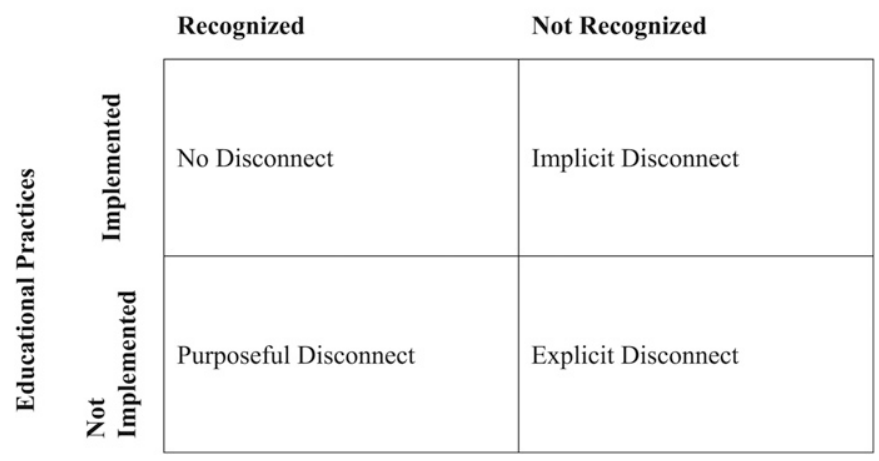

Figure 2. Levels of Disconnect Between Learning Theories and Educational Practices disconnect between the learning theories and educational practices (Figure 2). At the first level, explicit disconnect, learning theories are neither recognized nor implemented in educational practices. At the second level, implicit disconnect, the learning theories are not recognized explicitly but seem to be partially implemented implicitly. At the third level, purposeful disconnect, the learning theories are recognized, but there is a dearth of implementation. Finally, at the no disconnect level, learning theories are recognized and implemented comprehensively and explicitly in the educational practices.

\section{METHODS}

A qualitative research design was used to gain a detailed understanding of the elements of the communities of practice theory that are evident in the QU PharmD program and to examine the nature of the potential disconnect between learning theories and educational practices. ${ }^{13}$ Social constructivism was selected as the interpretative framework because it focuses on negotiating the social and 


\section{American Journal of Pharmaceutical Education 2020; 84 (9) Article 847515.}

subjective meanings of the world and, hence, is appropriate for exploring social theories of learning. ${ }^{12,31}$ Additionally, social constructivism's underlining assumptions about reality (ontology), knowledge (epistemology), values (axiology), and an approach to inquiry (methodology) align with the assumptions of the researchers and of the researched topics. For ontology, social constructivists argue that there are multiple subjective and objective realities, which are constructed through social interactions. The reality of the PharmD program was thus different for each participant because of their variable personal and professional experiences and the unique perspectives they had, and the researchers reported these different perspectives. For epistemology, social constructivists state that knowledge is socially constructed between the researchers and their research, depending on their norms. Each participant in this study had developed individual meanings related to the PharmD program; therefore, the researchers refer to participant quotes in the findings. For axiology, within social constructivism, researchers' values influence data interpretation. $^{12}$ Therefore, the researchers acknowledged the influence of the values of the participants and reflected on their own values. Finally, for the methodology, social constructivists argue that researchers use inductive and deductive reasoning to examine a topic within its particular context. Therefore, the researchers used inductive and deductive questioning and collected data using several methods.

A single descriptive instrumental case study approach was selected to achieve a state of methodological congruence between the research questions and research methods. ${ }^{13,32}$ This case study research led to the development of a case study-developed theory that described the role of learning theories in the educational practices of the QU PharmD program. ${ }^{33,30}$

Propositions are statements derived from theories, a review of the literature, or a personal experience. ${ }^{30}$ Propositions are vital for case study research because they direct attention to things that should be examined, reflect important theoretical issues, and emphasize sources of evidence, which facilitate analytical generalization. ${ }^{32} \mathrm{In}$ this case study, each element of the theoretical communities of practice-based framework ${ }^{9}$ has been reflected in a proposition statement that was subject to peer review before finalization (Table 3). These propositions were subsequently used in the development of topic guides.

Key administrative documents that describe the PharmD program were analyzed, including: the design document for the PharmD program (Design-D), CCAPP's accreditation preparation document (Preparation-D), and self-assessment of the PharmD program document (Selfstudy-D). Semi-structured interviews were conducted with key stakeholders, including the two PharmD program designers, a pharmacy education scholar, a CCAPP administrator, and a PharmD alumnus. Focus groups were conducted with participants who were similar in their experience, including students $(n=4)$, faculty members $(n=6)$, and preceptors $(n=15)$. Focus groups held with faculty members and students, and the interview with the alumnus took place at QU. Preceptor focus groups were conducted at QU and the hospital. The interviews with the designers, the CCAPP agent, and scholar were conducted either at QU or via Skype.

Two sampling strategies were used to recruit participants. The first was the maximum variation sampling strategy, represented by various PharmD program stakeholders who provided different perspectives based on their experiences. The second sampling strategy was key informant selection, represented by students, faculty members, preceptors, a PharmD alumnus, the PharmD program designers, an internationally renowned pharmacy education scholar, and a CCAPP administrator. The participants were contacted by email to invite them to participate in the research and to provide them with the participant information leaflet and consent forms. Upon acceptance, focus groups and interviews were recorded after notifying participants that recording was taking place. The recordings were then transcribed verbatim. ${ }^{34}$

Thematic analysis was used for data analysis using computer-assisted coding software, NVIVO for Mac, versions 10 and 11 (QSR International, www.qsrinternational. com). The propositions were used to deductively organize analytical priorities when examining the data. ${ }^{32}$ This analysis aimed to indicate whether each particular proposition had been implemented in the QU PharmD program. Inter-coder and intra-coder reliability testing were conducted to enhance the dependability of the research (Table 2 ). Inter-coder reliability testing was partially achieved by a peer researcher who coded, analyzed, and interpreted the data in the early stages and in selected elements of later stages of the research. Intra-coder reliability testing was achieved by coding the data for the first time, leaving it for approximately two weeks, and then independently recoding the same data, and comparing the coding results.

The rigor of this study was ensured by adhering to Lincoln and Guba's trustworthiness criteria, which include credibility, conformability, transferability, and dependability. ${ }^{13,35}$ The measures used to attempt various quality criterion are indicated in Table 2. Ethical approval was received from Qatar University's Institutional Review Board at QU.

\section{RESULTS}

The results were categorized according to the six communities of practice framework components, represented 


\section{American Journal of Pharmaceutical Education 2020; 84 (9) Article 847515.}

Table 2. Measures to Attempt Quality Criteria Was Ensured by Adhering to Lincoln and Guba's Trustworthiness Criteria

\begin{tabular}{|c|c|c|c|}
\hline \multicolumn{4}{|l|}{$\begin{array}{l}\text { Quality } \\
\text { Criterion }\end{array}$} \\
\hline Confirmability & $\begin{array}{l}\text { Audit trail: audio recordings, } \\
\text { transcripts, and coding are } \\
\text { available }\end{array}$ & $\begin{array}{l}\text { Research methods description: } \\
\text { comprehensive description of } \\
\text { research methods }\end{array}$ & $\begin{array}{l}\text { Data triangulation: multiple sources } \\
\text { of data and various participants } \\
\text { categories are utilized }\end{array}$ \\
\hline Dependability & $\begin{array}{l}\text { Peer review: oversight and } \\
\text { audit of the research } \\
\text { process was conducted by } \\
\text { peer researchers }\end{array}$ & $\begin{array}{l}\text { Inter-coder reliability testing: } \\
\text { partially achieved by a peer } \\
\text { researcher coding, analyzing, and } \\
\text { interpreting data in selected stages } \\
\text { of the research. Peer researchers } \\
\text { were involved in discussing the } \\
\text { collection, analysis, and } \\
\text { interpretation of data }\end{array}$ & $\begin{array}{l}\text { Intra-coder reliability testing: } \\
\text { achieved by coding the data for the } \\
\text { first time, leaving it for two weeks, } \\
\text { and then independently recoding } \\
\text { for the same data, and then } \\
\text { comparing the coding results. The } \\
\text { results of coding and recoding } \\
\text { matched }\end{array}$ \\
\hline Credibility & $\begin{array}{l}\text { Reflection recording: a } \\
\text { research diary is } \\
\text { maintained reflect on the } \\
\text { researcher's own influence } \\
\text { and biases }\end{array}$ & $\begin{array}{l}\text { Proper data analysis strategies: } \\
\text { interpretation of the data is ensured } \\
\text { to be correct, by following the } \\
\text { proper data analysis strategies, } \\
\text { relying on theoretical propositions } \\
\text { (deductive coding) }\end{array}$ & $\begin{array}{l}\text { Member/participant checking: } \\
\text { transcripts and findings were sent } \\
\text { to participants to confirm that they } \\
\text { reflected their perspectives. } \\
\text { Almost, all respondents agreed } \\
\text { with data analysis and } \\
\text { interpretation }\end{array}$ \\
\hline Transferability & $\begin{array}{l}\text { Data interpretation and } \\
\text { discussion: a case } \\
\text { study-developed theory } \\
\text { is created based on data } \\
\text { interpretation and discussion }\end{array}$ & $\begin{array}{l}\text { Recording research details: details } \\
\text { about the case study are provided } \\
\text { by describing the CoP learning } \\
\text { theory, the QU PharmD program, } \\
\text { and the "case" and its boundaries }\end{array}$ & $\begin{array}{l}\text { Research writing up: information } \\
\text { related to this case study was } \\
\text { recorded in a detailed write-up of } \\
\text { the research as a } \mathrm{PhD} \text { thesis and } \\
\text { research manuscript }\end{array}$ \\
\hline
\end{tabular}

by propositions, ${ }^{13}$ to emphasize whether the elements of the components were evident in the program. The choice of a specific proposition for a specific respondent group was based on their unique experiences in the PharmD program and was subject to peer review. For example, the propositions and the questions associated with them were different for students than for preceptors, based on their expertise (Table 3).

As represented in Table 4, the evidence of the communities of practice framework in the QU PharmD program falls into three categories, elements of communities of practice that were implicitly and fully evident, elements of communities of practice that were implicitly and partially evident, and elements of communities of practice that were not evident at all. Several factors affected the development of the analysis and interpretation cycles. Some of these factors were related to the researcher's previous experience in the program and understanding of the communities of practice framework. Other factors were related to the research process, such as the feedback received from respondents about the transcripts through member checking. For example, the designer suggested adding an analysis category that identified the communities of practice framework elements that were partially implemented instead of having categories for only fully implemented or non-implemented elements. Therefore, the researchers made the decision to categorize elements in the continuum "gray area" as implicitly and partially evident elements.

A few of the components of the enablers were partially evident, such as benchmarking to a successful educational model, integration with the CCAPP accreditation standards, and the provision of healthy communication. However, other components were less evident, such as the formation of a co-development team, faculty member involvement, and the presence of a policy about time regulations and student responsibilities, as demonstrated in the following designer's quote: "Preceptors wished to have students for a longer period, because students became independent only in their last week of rotation."

Some major challenges to communities of practice were evident, such as the limited number of preceptors, the practical placement integration in sequence and specialty, and the lack of understanding and communication about measures of the theory to faculty members and preceptors. For example, a faculty member said: "We are good teachers, but don't know if this is related to theory. We aren't trained as educators."

For the education process pillars, which included curriculum, teaching strategies, and assessment, key elements 


\section{American Journal of Pharmaceutical Education 2020; 84 (9) Article 847515.}

Table 3. Communities of Practice Framework Propositions and Respondent Categories

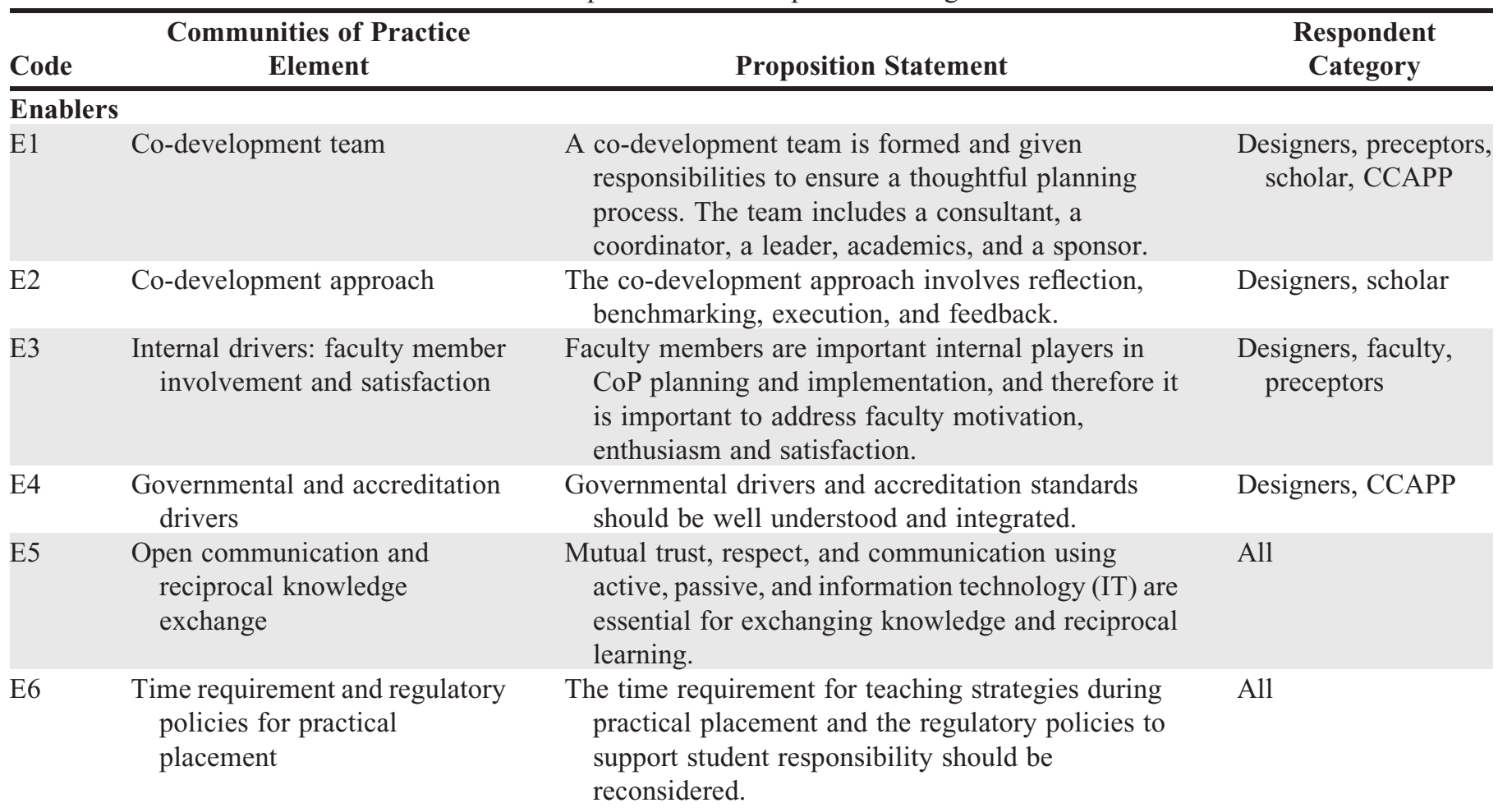

Challenges

$\mathrm{CH} 1$ Different interpretations of CoP theory

$\mathrm{CH} 2 \quad$ Time constraints

CH3 Students' lack of confidence due to lack in practical placement integration

CH4 Balancing size and composition
There are specific measures and outcomes of CoP that are communicated to all members.

The additional time commitment required for effective $\mathrm{CoP}$ implementation might be too much for members.

To increase students' confidence, it is important to introduce them to the CoP concept and to practical placements early and at different stages of their degree in an integrated fashion.

It is important to retain a balance between the number of employees in an institution and the typical number of members in CoP to ensure the expected proximity between members.
All

Faculty, scholar, designers, preceptors

Students, designers, scholar, alumna

Scholar, CCAPP

All important. Therefore, academic and practice mentors should understand their implications, and ensure that both types are measured.

Knowledge should be 'recontextualized' as students move between the classroom and workplaces, through student use of the workplace to socially link theory and practice.

In curriculum development, the practice placement timing, nature and duration should be properly planned, taking into consideration student goals and needs. 
American Journal of Pharmaceutical Education 2020; 84 (9) Article 847515.

Table 3. (Continued)

\begin{tabular}{|c|c|c|c|}
\hline Code & $\begin{array}{c}\text { Communities of Practice } \\
\text { Element }\end{array}$ & Proposition Statement & $\begin{array}{c}\text { Respondent } \\
\text { Category }\end{array}$ \\
\hline $\mathrm{C} 4$ & Dual accreditation & $\begin{array}{l}\text { Compatibility between professional licensing, } \\
\text { accrediting body requirements and course } \\
\text { requirements for dual accreditation serves the } \\
\text { learners' best interests. }\end{array}$ & $\begin{array}{l}\text { Designers, scholar, } \\
\text { CCAPP }\end{array}$ \\
\hline $\mathrm{C} 5$ & $\begin{array}{l}\text { Partnerships between the } \\
\text { university and practice sites }\end{array}$ & $\begin{array}{l}\text { CoP theory encourages the integration of academics } \\
\text { and practitioners, recognizing the importance of } \\
\text { their skills and knowledge in developing a practice- } \\
\text { based learning. }\end{array}$ & $\begin{array}{l}\text { Preceptors, faculty, } \\
\text { CCAPP }\end{array}$ \\
\hline C6 & Curriculum integration & $\begin{array}{l}\text { Practical placements provide an example of an } \\
\text { integrated curriculum where courses are merged } \\
\text { within the context of pharmacy practice, to allow } \\
\text { students to apply knowledge in practice. }\end{array}$ & $\begin{array}{l}\text { Students, designers, } \\
\text { faculty, scholar, } \\
\text { alumna, CCAPP }\end{array}$ \\
\hline
\end{tabular}

Teaching Strategies

TS1 Practical placement environment (or learning environment)

TS2 Mentoring strategies

TS3 Shadowing

TS4 Peer support

TS5 Socialization and acceptance
An appropriate learning environment is fundamental in CoP, such as healthy relationship between students and mentors and health professionals, and the feeling of belonging.

The students undergo various mentoring strategies that progress with their competence, such as demonstration, modelling, coaching, scaffolding, reflection and exploration.

Mentors from the practice sites should shadow faculty while they teach in classrooms and faculty should shadow mentors in the practice site to ensure concepts integration.

Peer support reinforces the social nature of learning through sharing knowledge and experience, learning from peers, providing support, and developing relationships.

Social and professional acceptance are linked because student presence at the practice site increases student confidence and competence expected for professional acceptance.
Students, preceptors, scholar, CCAPP, designers, alumna

Students, preceptors, designers, faculty, alumna

Faculty, preceptors, students, alumna

Students, preceptors, scholar, designers

Preceptors, students, alumna

Preceptors, designers faculty, scholar orienting newly appointed educators to the expectations of the assessment and mentoring them in the assessment process.

A2 Ensure valid and reliable assessment tools

Assessment tools are valid, reliable, and appropriate for use in progress decisions.

A3 Authentic assessment activities with progressively increased difficulty level

Assessment tools are authentic and their level of difficulty progressively and gradually increases.

Collaboration between academics and practitioners in assessment leads to sharing experiences, trusting relationships, discussions, and problem-solving, without barriers. 
American Journal of Pharmaceutical Education 2020; 84 (9) Article 847515.

Table 3. (Continued)

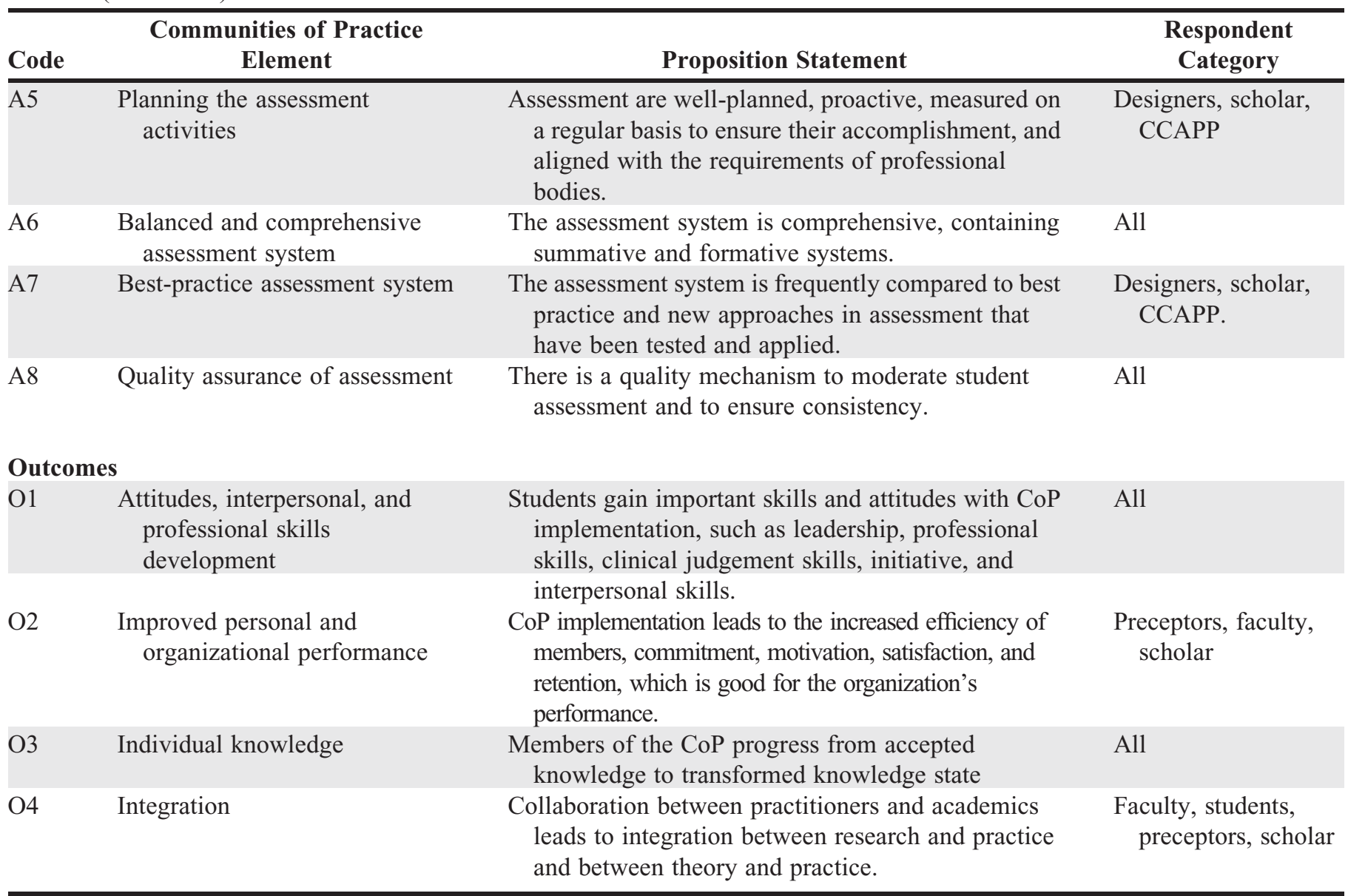

of the curriculum, such as knowledge recontextualization and application of the curriculum in practical placements and vertical integration, appear to have been implemented. However, the presence of other elements was not consistently evident, such as the compatibility of curriculum design with CCAPP accreditation standards and with the professional licensing body, informal learning, and considering student needs when planning placement details, as expressed in the following student's quote: "Students overseas prioritize rotations, and are placed accordingly. Wouldn't be helpful if we choose our preferred specialty?"

For teaching strategies, social and professional acceptance was evident but with several inconsistent practices. Collaboration between faculty liaisons and practitioners did not occur. Furthermore, other elements under teaching strategies were not fully evident, such as progressive mentoring strategies, peer support, and shadowing between practitioners and academics. For example, an alumna mentioned: "Now for students teaching each other, maybe we used to have this, but unplanned."

For assessment, the PharmD program planned effective assessment measures and partially implemented preceptors' orientation to students' assessment and authenticity in assessment activities. However, other elements had not been implemented, such as collaboration between faculty members and preceptors in assessment, a comprehensive assessment system, the formulation of a quality mechanism, and assurance of the reliability and validity of the assessment tools. The latter was mentioned by one of the preceptors: "The assessment tools go into too much details. Some of these details are not applicable to all practice places."

Because not all communities of practice elements had been implemented, we expected that not all communities of practice outcomes had been fully achieved. For example, the data suggest that the integration of theory, practice, and research has not taken place comprehensively. In addition, job efficiency and satisfaction did not increase, as articulated by one of the preceptors: "We, as preceptors, need to get the benefit from being adjunct faculty. Academically, we are not gaining."

\section{DISCUSSION}

The newly developed theoretical communities of practice framework ${ }^{9}$ was used to examine evidence of the 
American Journal of Pharmaceutical Education 2020; 84 (9) Article 847515.

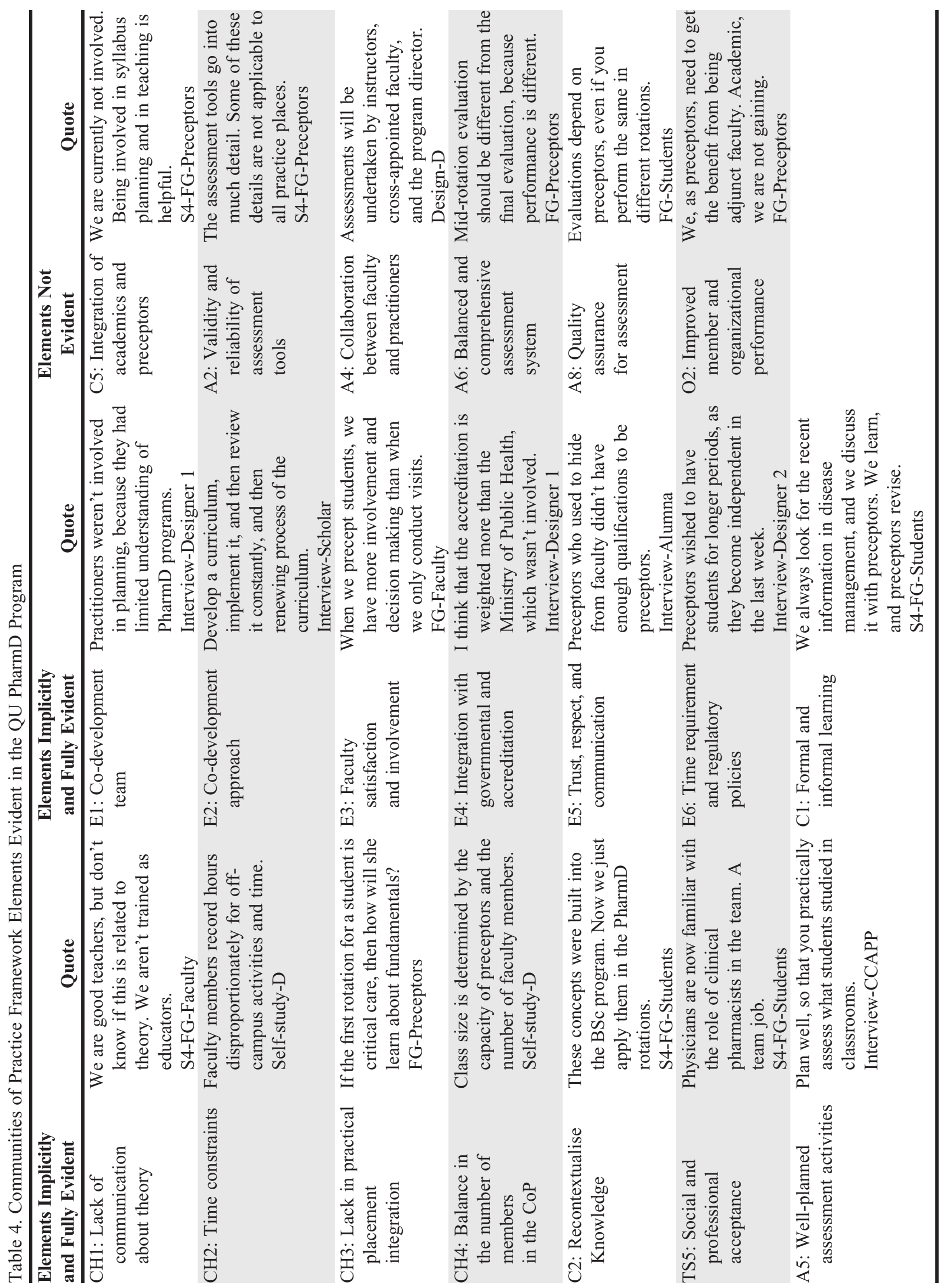




\section{American Journal of Pharmaceutical Education 2020; 84 (9) Article 847515.}

communities of practice framework in the QU PharmD program. The findings of this study suggest that, despite the PharmD program's compliance with QU quality assurance policies, accreditation by the CCAPP agency, and the graduation of quality clinical pharmacists, major pedagogical issues exist in the program. The pedagogical issues observed in our study suggest that theoretical programs sometimes lack an alignment with the outcomes that reflect assessment and teaching strategies, and with the expected supporting activities, which are essential to sustainable program design. ${ }^{36,37}$

The results suggest that all enablers fall into the "implicitly partially evident" category, which means that they did not exist throughout the QU PharmD program. Therefore, several elements of the education process pillars were only partially evident or completely absent. For example, the lack of clear preceptor involvement on the co-development team (E1) during the design phase led to a continued lack of collaboration with faculty liaisons on other educational processes, such as shadowing (TS3), curriculum planning (C5), and assessment (A4). The significance of the preceptor role in teaching and learning activities has been emphasized by previous research. ${ }^{38}$ For example, when nursing students spend longer periods of time with their mentors, they are exposed to various aspects of professional practice from which they learn the role of a qualified nurse. ${ }^{38}$ Furthermore, the integration of preceptor and university communities to form an "academy of learning" is beneficial for preceptors, the university, and the students because it reduces the disconnect between health educator standards at universities and actual professional practices. ${ }^{39}$

The role of the CCAPP accreditation standards was evident in the overall design of the QU PharmD program (E3), which has led to an alignment between the accreditation standards and the course requirements in curriculum planning (C4). However, E3 was categorized as implicitly and partially evident because of the absence of an equally important alignment of the design of the QU PharmD program with governmental drivers and requirements. The importance of governmental support for communities of practice initiatives was emphasized by Kothari and colleagues who indicated that communities of practice efforts to stimulate practice changes should be supported by the health system, health institutions, and the government. ${ }^{40}$

All challenges to the successful implementation of communities of practice within an academic program, or academic institution were evident in the QU PharmD program. The different interpretation of communities of practice learning theory and a dearth of communication about its outcomes $(\mathrm{CH} 1)$ has prevented the development of several aspects of the educational process pillars. The findings suggest that designers, policy makers, faculty members, and preceptors were originally not trained as educators, and that resulted in a lack of consideration for the significance of learning theories in program design. For policy makers, this lack of consideration has been reflected in the absence of a reference to pedagogy in governmental and accreditation drivers, which made the consideration of the learning theories by the designers and educators unnecessary. Therefore, some practices that emerge from communities of practice learning theories are implemented by default in the QU PharmD program, without a recognition of their relationship to a particular learning theory. These educational practices may have been evident in other PharmD programs and were thus seen as best practices to adopt and adapt. ${ }^{1,41}$

We therefore propose that the QU PharmD program is at the second level of disconnect, implicit disconnect, in which communities of practice or other learning theories are not recognized explicitly but are partly and implicitly implemented in educational practices. For example, knowledge recontextualization (C2) and social and professional acceptance (TS5) had been generally implemented, with few inconsistencies. However, because the evidence of their existence was not associated with an intention to apply a theory, the existence of these elements is implicit. This implicit implementation has, in some cases, led to the achievement of the desired outcome, such as skills and disposition development (O1), but not to the achievement of other desired outcomes, such as improved member and organizational performance (O2). This finding was supported by Spilg and colleagues who argued that the social aspects of learning and some elements of communities of practice theory are "embedded" key components of the medical education tradition. ${ }^{42}$ The significance of aligning educational practices with learning theories and of communicating pedagogical principles by Gonczi, who indicated that the implementation of communities of practice is expected to facilitate the development of preceptors' skills, which are required for their professional competence ${ }^{43}$ and work satisfaction as practice educators. ${ }^{44}$

Mukhalalati and Taylor argued that using one learning theory, communities of practice, in the design and application of the PharmD program enhances the consistency among curriculum planning, teaching strategies, and assessment activities. ${ }^{9}$ This argument is supported by previous literature; Sadideen and Kneebone explained that creating an educational framework based on one learning theory could facilitate the prediction of the best teaching strategies in a particular setting, such as practical skills teaching, which facilitates consistency. ${ }^{45}$ 


\section{American Journal of Pharmaceutical Education 2020; 84 (9) Article 847515.}

Likewise, Botma and colleagues noted that teaching and learning activities should ideally be aligned with outcome and assessment tasks through the development of conceptual frameworks for educational design. ${ }^{46}$

The pedagogical issues associated with a lack of consideration of communities of practice learning theory in the design and implementation of the QU PharmD program have led to the proposal of a case study-developed theory about the interplay between learning theories and educational practices that has three main aspects. The first aspect addresses the need for the explicit rather than implicit implementation of learning theories in education programs, suggesting that the education program should aim to achieve the no disconnect level. The second aspect addresses the need for the comprehensive rather than partial implementation of a suitable learning theory in an educational program, because the components of learning theories tend to be interrelated, and this interrelation impacts the consistency of student learning. The third aspect addresses the appropriateness of using communities of practice theory for designing and analyzing PharmD programs. With these main aspects in mind, through this case study we developed the following theory: The design and practices of educational programs should be based on the comprehensive and explicit implementation of an appropriate learning theory, which is potentially the communities of practice learning theory in PharmD programs.

This case study provides a detailed description of the practical application of the communities of practice instrument in the analysis of the QU PharmD program, demonstrating the efficacy of the communities of practice framework and promising the transferability of this application to other settings. In that regard, accreditation agencies, local governmental authorities, and educational institutions can collaborate in developing their professional and educational standards to ensure the graduation of competent practitioners. Additionally, the academic sector can provide undergraduate and graduate students with courses that outline educational, pedagogical, and learning concepts that prepare students to assume a future role as educators. Furthermore, we recommend that the academic sector pay more attention to the key role of preceptors by providing them with mandatory professional development activities and by orienting them, mentoring them, and monitoring their preceptorship performance, and by rewarding them professionally and financially for their important roles Moreover, we recommend that the academic sector support the active participation of students at practice sites by ensuring proper sequencing and extending the duration of their placements. Finally, the academic sector should initiate and support the integration of the practice and academic sectors, and mandate collaboration between academics and preceptors.

This study had a few limitations. During data collection, policymakers in Qatar were not considered for data collection. This is because the researchers considered that the deep understanding of the QU PharmD program designers of the role of policymakers in the pharmacy profession to be adequate. However, gaining the perspectives of policy makers could have provided a deeper understanding of the role of governmental drivers in the disconnect between theory and practice and its consequences. Furthermore, some elements of the communities of practice framework were difficult to categorize as being either evident or not evident in the PharmD program because they represented a "gray area"; therefore, the researchers created a category for "partially evident" elements. The researchers' interpretation of this gray area could have been potentially subjective to personal biases. However, the undertaken dependability measures decreased the influence of this limitation. Finally, the designers and faculty may have been using a different learning theory than communities of practice or a combination of more than one theory. However, this research focused on the use of one learning theory, communities of practice, to enhance consistency among curriculum, teaching strategies, and assessment in a college of pharmacy.

\section{CONCLUSION}

This research examined evidence of the implementation of communities of practice learning theory in the design of educational practices within the QU PharmD program by taking a case study research approach and using the communities of practice theory-informed framework as a theoretical instrument. This analysis demonstrated the effectiveness of the communities of practice framework for this analysis and shed light on the nature of the disconnect between communities of practice learning theory and educational practices. This research concluded that the disconnect in the QU PharmD program was at the "implicit disconnect" level, which means that some elements of the communities of practice framework were implicitly evident in the program. This conclusion facilitated the creation of the case study-developed theory about the significance of the full and explicit implementation of learning theory in the design and application of educational practices. Finally, the study results call for a better integration of academic, practice, accreditation, and governmental sector efforts in pharmacy educational reform initiatives to achieve the optimal connection between learning theories and educational practices in a PharmD program. 


\section{American Journal of Pharmaceutical Education 2020; 84 (9) Article 847515.}

\section{ACKNOWLEDGMENTS}

The authors would like to acknowledge the funding agency: Qatar University, and the efforts of Ms. Sara Sami Gadelhak Gomaa Elshami, research assistant, for helping in redrawing the figures in a clearer way using PowerPoint software.

\section{REFERENCES}

1. Wilbur K, Paiva M, Black E. Pharmacy student and preceptor impressions of faculty liaison visits to experiential training sites. $\mathrm{Am} \mathrm{J}$ Pharm Educ. 2015;79(9):134.

2. Wilbur K. summative assessment in a doctor of pharmacy program: a critical insight. Adv Med Educ Pract. 2015;6:119-126.

3. General Secretariat for Devlopment Planning. Qatar National Vision 2030. Doha: General Secretariat for Development; 2008. 4. PhD in Pharmaceutical Sciences. Qatar University College of Pharmacy. http://www.qu.edu.qa/pharmacy/departments/programs/ phd-in-pharmaceutical-sciences. Accessed August 29, 2020.

5. Kheir N, Fahey M. Pharmacy practice in Qatar: challenges and opportunities. South Med Rev. 2011;4(2):92-96.

6. Canadian Council for Accreditation of Pharmacy P. Guidance for the accreditation standards for the first professional degree in pharmacy programs. http://ccapp-accredit.ca/wp-content/uploads/ 2016/01/CCAPP_accred_standards_degree_2014.pdf. Revised 2014. Accessed August 29, 2020.

7. Accreditation Council for Pharmacy Education. Accreditation standards and key elements for the professional program in pharmacy leading to the doctor of pharmacy degree. https://www.acpe-accredit. org/pdf/GuidanceforStandards2016FINAL.pdf. Published 2015. Accessed August 29, 2020.

8. Waterfield J. Two approaches to vocational education and training. A view from pharmacy education. J Vocat Educ Train. 2011;63(2):235-246.

9. Mukhalalati BA, Taylor A. The development of a theory-informed Communities of Practice Framework for pharmacy and other professional healthcare education programmes. Pharm Educ. 2018;18:166-180.

10. Duncan-Hewitt W, Austin Z. Pharmacy schools as expert communities of practice? A proposal to radically restructure pharmacy education to optimize learning. Am J Pharm Educ. 2005;69(3):54.

11. Noble C, Shaw PN, Nissen L, Coombes I. Curriculum for uncertainty: certainty may not be the answer. Am J Pharm Educ. 2011;75(1):13.

12. Mukhalalati B, Awaisu A. Principles, paradigms, and application of qualitative research in pharmacy practice. In: Babar ZUD, et al. (eds). Encyclopedia of Pharmacy Practice and Clinical Pharmacy. MA: Elsevier; 2019:62-172.

13. Creswell JW. Qualitative Inquiry and Research Design: Choosing Among Five Approaches. CA: SAGE Publications; 2013.

14. Arab M, Ghavami B, Lakeh MA, Esmaeilpoor S, Yaghmaie M, Hosseini-Zijoud S-M. Learning theory: narrative review. Int J Med Rev. 2015;2(3):291-295.

15. Taylor DC, Hamdy H. Adult learning theories: implications for learning and teaching in medical education: AMEE Guide No. 83. Med Teach. 2013;35(11):e1561-e1572.

16. Torre DM, Daley BJ, Sebastian JL, Elnicki DM. Overview of current learning theories for medical educators. Am J Med. 2006; 119(10):903-907.
17. Mukhalalati BA, Taylor A. Adult learning theories in context: a quick guide for healthcare professional educators. J Med Educ Curric Dev. 2019;6:2382120519840332.

18. Vygotsky L. Interaction between learning and development. Readings on the Development of Children. 1978;23(3):34-41.

19. Lave J, Wenger E. Situated Learning: Legitimate Peripheral Participation. NY: Cambridge University Press; 1991.

20. Wenger E. Communities of Practice: Learning, Meaning, and Identity. NY: Cambridge University Press; 1998.

21. Wenger E, McDermott RA, Snyder W. Cultivating Communities of Practice: A Guide to Managing Knowledge. MA: Harvard Business Press; 2002.

22. Wenger E. Communities of practice and social learning systems: the career of a concept. In: Social Learning Systems and Communities of Practice. London: Springer; 2010: 179-198.

23. Austin Z, Duncan-Hewitt W. Faculty, student, and practitioner development within a community of practice. Am J Pharm Educ. 2005;69(3):55.

24. Noble C, Shaw PN, Nissen L, Coombes I, O'Brien M. Curriculum for uncertainty: certainty may not be the answer. $\mathrm{Am} J$ Pharm Educ. 2011;75(1):13a.

25. Andrew N, Tolson D, Ferguson D. Building on Wenger: communities of practice in nursing. Nurse Educ Today. 2008; 28(2):246-252.

26. Noble C, Coombes I, Nissen L, Shaw PN, Clavarino A. Making the transition from pharmacy student to pharmacist: Australian interns' perceptions of professional identity formation. Int $J$ Pharm Pract. 2015;23(4):292-304.

27. Austin Z, Ensom MH. Education of pharmacists in Canada. Am J Pharm Educ. 2008;72(6):128.

28. Frankel G, Louizos C, Austin Z. Canadian educational approaches for the advancement of pharmacy practice. Am J Pharm Educ. 2014;78(7):143.

29. Garrard J. Health Sciences Literature Review Made Easy. London: Jones \& Bartlett Publishers; 2013.

30. Baxter P, Jack S. Qualitative case study methodology: study design and implementation for novice researchers. Qual Rep. 2008;13(4):544-559.

31. Awaisu A, Mukhalalati B, Ibrahim MIM. Research designs and methodologies related to pharmacy practice. In: Babar ZUD, et al. (eds). Encyclopedia of Pharmacy Practice and Clinical Pharmacy.

MA: Elsevier; 2019:7-21.

32. Yin RK. Case Study Research: Design and Methods. London: Sage Publications; 2014.

33. Baker GR. The contribution of case study research to knowledge of how to improve quality of care. BMJ Qual Saf. 2011;

20(Suppl 1):i30-i35.

34. Miles MB, Huberman AM, Saldana J. Qualitative Data Analysis: A Method Sourcebook. CA: Sage Publications; 2014: 275-322.

35. Lincoln YS, Guba EG. Naturalistic Inquiry. CA: Sage Publications; 1985.

36. Morcke AM, Dornan T, Eika B. Outcome (competency) based education: an exploration of its origins, theoretical basis, and empirical evidence. Adv Health Sci Educ Theory Pract. 2013; 18(4):851-863.

37. Taylor DCM, Hamdy H. Adult learning theories: implications for learning and teaching in medical education: AMEE Guide No. 83. Med Teach. 2013;35(11):e1561-e1572.

38. Morley D. Applying Wenger's communities of practice theory to placement learning. Nurse Educ Today. 2016;39:161-162. 


\section{American Journal of Pharmaceutical Education 2020; 84 (9) Article 847515.}

39. Weston KM, Hudson JN. Clinical scholarship among preceptors supervising longitudinal integrated medical clerkships in regional and rural communities of practice. Aust J Rural Health. 2014; 22(2):80-85.

40. Kothari A, Boyko JA, Conklin J, Stolee P, Sibbald SL. Communities of practice for supporting health systems change: a missed opportunity. Health Res Policy Syst. 2015;13(1):33. 41. Janke KK, Seaba HH, Welage LS, et al. Building a multiinstitutional community of practice to foster assessment. Am J Pharm Educ. 2012;76(4):58.

42. Spilg E, Siebert S, Martin G. A social learning perspective on the development of doctors in the UK National Health Service. Soc Sci Med. 2012;75(9):1617-1624.

43. Roberts GI. Communities of practice: Exploring enablers and barriers with school health clinicians. Explorer les facteurs favorables et défavorables à la participation aux communautés de pratique avec des cliniciens de la santé en milieu scolaire. Can J Occup Ther. 2015;82(5):294-306.

44. Bentley C, Browman GP, Poole B. Conceptual and practical challenges for implementing the communities of practice model on a national scale-a Canadian cancer control initiative. BMC Health Serv Res. 2010;10(1):3.

45. Sadideen H, Kneebone R. Practical skills teaching in contemporary surgical education: how can educational theory be applied to promote effective learning? Am J Surg. 2012;204(3): 396-401.

46. Botma Y, Van Rensburg GH, Coetzee IM, Heyns T. A conceptual framework for educational design at modular level to promote transfer of learning. Innov Educ Teach Int. 2015;52(5): 499-509. 